\title{
SELECTION OF WELDING CONDITIONS FOR MINIMIZING THE RESIDUAL STRESSES AND DEFORMATIONS DURING HARD- FACING OF MILD STEEL
}

UDC 691.714:52-334.2

Original scientific paper

\begin{abstract}
Summary
Hard-facing process is widely used for improving the wear resistance of mild steel. During the application of hard-facing, due to high temperatures, residual stresses and deformations may occur. The tensile residual stresses may cause crack propagation on the hard-faced part. The purpose of this study is to utilise minimum computer work for minimizing these residual stresses and deformations during the hard-facing of mild steel. The fully coupled transient heat transfer and structural analysis was performed for calculations. The double-ellipsoidal moving heat source was utilised to simulate the heat input from the gas metal arc welding (GMAW). Only eight numerical simulations were performed to minimize the computer work; the grey relational analysis was used for minimizing both the residual stresses and deformations. Welding speed, welding current, and welding pattern were considered as changing parameters. At the end of the numerical and statistical solutions, it is observed that heat input should be kept minimum to minimize the stresses and deformations. But it is obvious that the heat input must provide a temperature greater than the melting point. Straight patterns always produce better results for minimizing stresses and deformations. Transverse stress at the beginning and end of the longitudinal path gets higher significantly after cooling. Cooling does not affect the total deformation.
\end{abstract}

Key words: $\quad$ Hard-facing; grey relational analysis; residual stresses; deformations; moving heat source; GMAW

\section{Introduction}

Most of the hard-facing applications are performed by the arc welding processes commonly known as gas tungsten arc welding (GTAW), shielded metal arc welding (SMAW), or gas metal arc welding (GMAW). There are a considerable number of modeling efforts for the arc welding processes in the literature. Some authors dealt with only the thermal part of the problem. Goldak et al. proposed a new geometrical method to simulate the heat input during the arc welding processes [1]. Since then, their model, which is called the double ellipsoidal moving heat source model, has been used by many authors. The effects of welding conditions and heat source parameters on temperature variations in butt joint welding were analyzed by Gery et al. [2]. They concluded that welding conditions and heat source parameters influence peak temperatures in the fusion zone (FZ) and affect the welded plate's transient temperature distributions. 
Ghosh and S. Chattopadhyaya proposed a new kind of heat source [3]. In their work, they utilised a conical Gaussian heat distribution to simulate the heat input during the submerged arc welding (SAW) process. Their results matched the experimental ones. Similar and dissimilar butt joints of the GTAW welding process were analyzed by some authors [4]. Such authors used ABAQUS software for simulation, worked with St 37 and AISI 304 sheets of steel, and concluded that the peak temperatures in AISI 304 are more significant than St 37. Their reasoning behind this the thermal properties differ from each other. An analytical method to simulate the transient temperature field for submerged arc welding was proposed and gave good results [5]. Garcia-Garcia et al. proposed an elliptic paraboloid heat source model [6]. Garcia-Garcia et al. studied the GTAW process with the help of the finite volume method. Design of experiments (DOE) technique simulates the temperature distribution in laser beam welding [7].

Alternative researchers dealt with both the thermal and structural parts of the modeling efforts in arc welding. Fanous et al. utilised element birth and element movement techniques to simulate the filler metal and welding [8]. It was concluded that the element movement technique was better than the other technique. Thermal elastic-plastic simulation of the arc welding process was studied by further researchers [9] who predicted the deflections in large structures very successfully. Deaconu made a structural analysis to simulate the distortions and residual stresses in welded plates [10]. SMAW of carbon steel plates was studied, and the residual stresses were predicted successfully in a research article [11]. Jeyakumar et al. studied ASTM36 steel plates to analyze weldment's structural behavior [12]. In their analysis, they found that even a 2-D model can predict the residual stresses successfully. Butt-welded IN716 plates were studied by some authors [13] and predicted that the tensile stresses near the weld centerline and compressive stresses away from it, which were observed in the experimental results. In a study using numerical simulation and experimental validation, authors concluded that longitudinal and circumferential stresses performed on the inner and outer surfaces and the radial direction revealed a considerable increase in weld speed and power [14]. Darmadi et al. utilised a mixed heat source model, which gave a well-matched temperature distribution and weld pool shape [15]. A mathematical model of a double ellipsoidal moving heat source has been used to simulate the transient thermal analysis by finite element method [16]. They exploited temperature distributions as thermal loads in a mechanical analysis to predict the plate distortions.

Nezamdost et al. proposed a new kind of moving heat source model to simulate SAW [17]. The fusion zone boundaries and the residual stresses were guessed very successfully. A group of researchers studied the TIG welding process of a stainless steel pipe [18]. They found that residual stress changes from compressive to tensile from outer to inner surface after the welding. AISI 316L steel was butt-welded, and the residual stresses were measured [19]. Only a small percentage of discrepancy was obtained. Some authors analyzed the GTAW welding of AISI 314 steel [20]. Model solutions show that the longitudinal residual stresses get smaller with heat input. With the heat input increasing, the tensile and compressive residual stresses are decreased. The transverse residual stresses get smaller with heat input. Butt-welded thin titanium plates were investigated both experimentally and numerically [21]. The longitudinal stress along the weld centerline was tensile, but it was compressive away from it.

Balram and Rajyalakshmi studied the multi-pass arc welding of dissimilar metals, and their model results are in good match with experiments [22]. Double-pass GTAW welding of aluminum plates was studied by other authors [23]. The model well predicted residual stresses and distortions. Prediction of temperature distribution and displacement in SAW was performed by Arora et al. [24] where they used DOE method not to make many calculations. Their results are in good agreement with the experiments. 
Some researchers dealt with hard-facing and other surface processing techniques. The details about these studies can be found in the next part. Wu et al. studied the modeling of the hard-facing phenomenon [25] where they concluded that the effects of the base metal thickness were dependent on the thickness. When the sample changed from thick to thin, the residual stresses in the hard-facing layer are reduced. Yang et al. studied the residual stresses in a hard-faced steel specimen [26]. A literature survey about surfacing processes yields Cordovilla et al. 's work dealing with laser surface hardening [27], El-Sayed, Shash, and AbdRabou's work on friction stir processing [28], and Zanger et al. 's work dealing with a stream finishing process [29]. Ramesh prepared a review study on hard-facing [30]. He mentioned processes and materials utilised in hard-facing. Lazic et al. also made an experimental study of the deformations at elevated temperatures during steels' hard-facing [31]. Lazic et al. studied the residual stresses between the hard-facing layers [32]. Zargar et al. studied the effects of the welding sequence on the distortions. They stated that the welding sequence significantly affected the distribution and the magnitude of welding-induced vertical deflection. [33]. Pandey et al. investigated the influence of preheating the filler metal on the distortions [34] where results revealed that there is a reduction in weld-induced distortion when the filler wire is preheated.

In the previous paragraph, one can find studies of hard-facing from the literature. Only one of the studies [33] involves how the welding sequence influences residual stresses and deformations. In this present work, low carbon steel's hard-facing process is investigated to minimize the residual stresses and deformations. The present work does not consider the filler material, only melting of the base metal is taken into account. The effect of the welding sequence, welding current, and welding speed was analyzed. The numerical technique was supported by a statistical method to accomplish this minimization.

\section{Numerical Procedure}

The most critical input of the GMAW hard-facing process is the transient heat generated by the arc. According to the most popular and referred work of Goldak et al., the double ellipsoidal moving heat source can be written in the appropriate form for the numerical domain in this present work [1] (Equations 1 and 2).

$$
\begin{aligned}
& q_{f}(x, y, z)=\frac{6 \sqrt{3}\left(f_{f} Q\right)}{a b_{f} c \pi \sqrt{\pi}} \exp \left(-\frac{3 x^{2}}{a^{2}}-\frac{3(y+v(\tau-t))^{2}}{b_{f}{ }^{2}}-\frac{3 z^{2}}{c^{2}}\right) \\
& q_{r}(x, y, z)=\frac{6 \sqrt{3}\left(f_{r} Q\right)}{a b_{r} c \pi \sqrt{\pi}} \exp \left(-\frac{3 x^{2}}{a^{2}}-\frac{3(y+v(\tau-t))^{2}}{b_{r}{ }^{2}}-\frac{3 z^{2}}{c^{2}}\right)
\end{aligned}
$$

Here, subscripts $f$ and $r$ represent front and rear, $x, y, z$ are cartesian coordinate axes, $a, b$ and $c$ are the heat source parameters. $Q$ can be calculated by multiplying efficiency, voltage, and ampere. $\tau$ is the lag factor needed to define the position of the heat source at time $\mathrm{t}=0 . v$ is the welding speed. The heat input is depicted in Figure 1 [35]. 


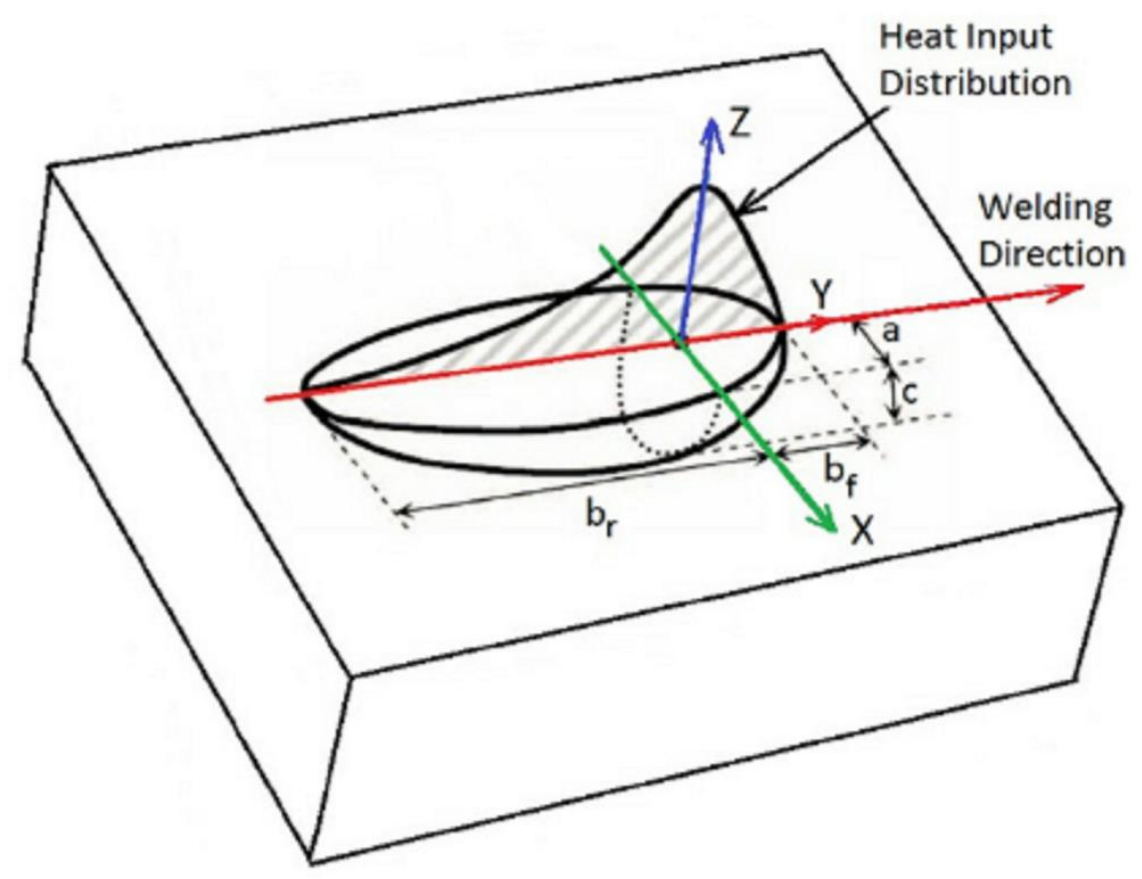

Figure 1. Schematic view of the double ellipsoidal moving heat source [35].

The thermal part of the welding simulation involves conduction, convection, and radiation. The model's structural part considers the elastic strain, plastic strain, and thermal strain (Equation 3).

$$
\varepsilon_{\text {total }}=\varepsilon_{\text {elastic }}+\varepsilon_{\text {plastic }}+\varepsilon_{\text {thermal }}
$$

Elastic strain is simulated using the isotropic Hooke's law with temperature-dependent Young's modulus and Poisson's ratio. The thermal strain is calculated using the temperaturedependent coefficient of thermal expansion. For the plastic strain, a plastic model is employed with von Mises yield criterion, temperature-dependent mechanical properties, and bi-linear isotropic hardening model. Zhang and Wang also utilized the same equation (Equation 3) for modeling the residual stresses in welded structures [36]. According to their work thermal strain can be calculated using the thermal expansion coefficient. The same applies to the present work. Creep and phase transformation induced strains are also ignored in both studies.

The coupling between the thermal and structural parts was performed using temperaturedependent material properties such as thermal expansion coefficient, elasticity modulus, and Poisson's ratio. Plastic deformations caused by the high heat input can cause a slight temperature change. Two-way coupling makes it possible for the strain work to affect the temperature field; however, the thermal field affects the structural part.

The problem domain is a $300 \times 100 \times 8 \mathrm{~mm}$ mild steel domain. The welding patterns, meshing, dimensioning, and paths for calculating transverse and longitudinal residual stresses, and deformations can be seen in Figures $2 a, 2 b$, and $2 c$. The structural boundary condition fixed supports are depicted in Figure 2d. The mesh size was chosen as $3 \mathrm{~mm}$ according to similar studies conducted by Fang et al. [37] and Andhale et al. [38]. The hard-facing simulation was conducted as a line heating problem without taking into account the filler material. 


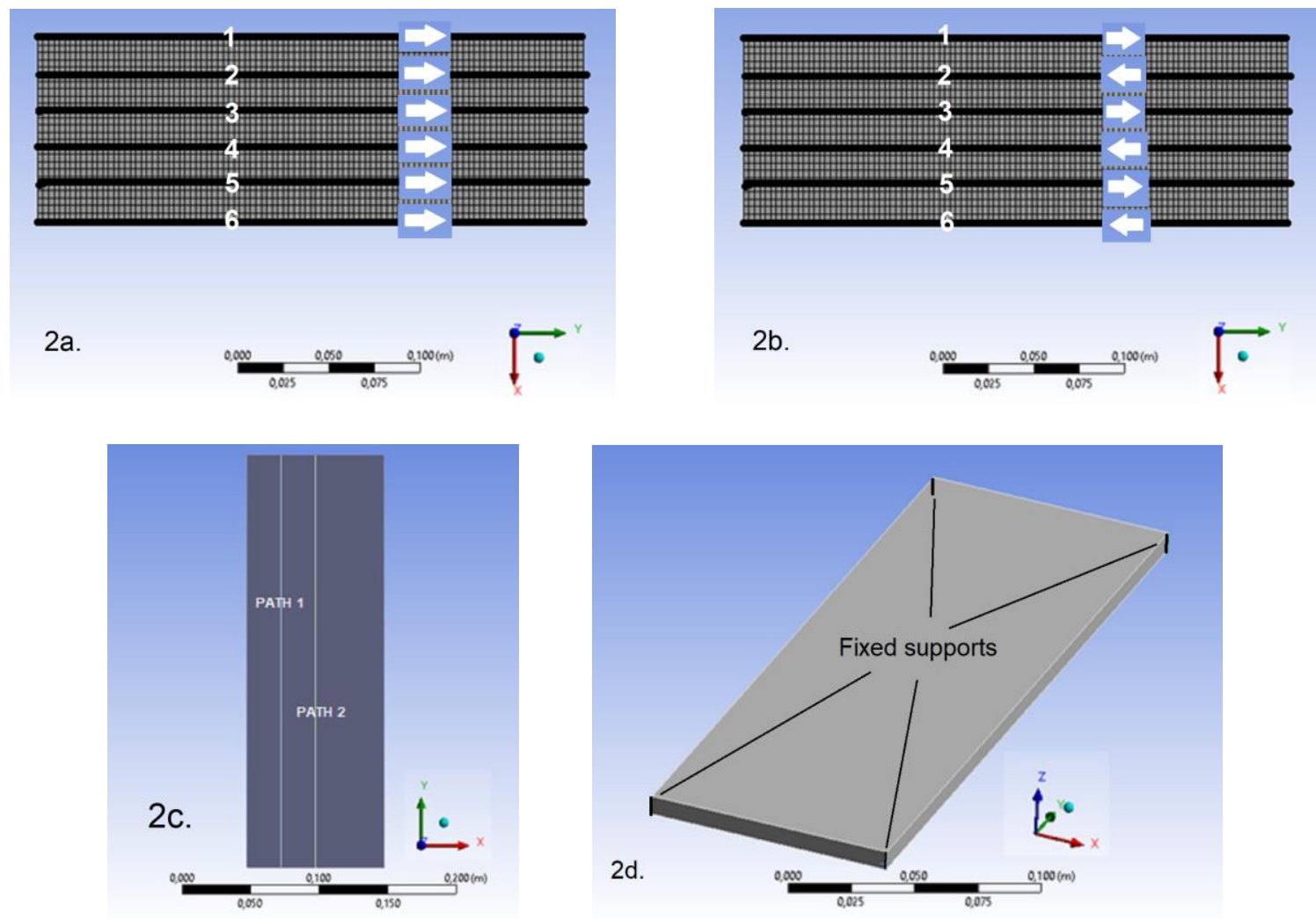

Figure 2 a. Straight welding pattern and mesh, b. Reverse welding pattern and mesh, c. Welding paths, d. Position of fixed supports.

The welding and heat source parameters are tabulated in Table 1. The thermal and structural properties of mild steel are given in Table 2. The Young's modulus is taken as 200 $\mathrm{GPa}$, and the tangent modulus for the bi-linear isotropic hardening model is chosen as $2 \mathrm{GPa}$. These moduli could not be taken as temperature-dependent because the model did not converge. The yield strength (YS) and the ultimate tensile strength (UTS) of A36 steel are taken as $250 \mathrm{MPa}$ and $500 \mathrm{MPa}$, respectively. The composition of A36 steel is tabulated in Table 3.

Table 1. The Goldak double ellipsoidal parameters for the welding simulation [24].

\begin{tabular}{|c|c|}
\hline$a$ (parameter in x-direction) & $6 \mathrm{~mm}$ \\
\hline$b_{f}$ (parameter in y-direction, front) & $4 \mathrm{~mm}$ \\
\hline$b_{r}$ (parameter in y-direction, rear) & $10 \mathrm{~mm}$ \\
\hline$c$ (parameter in z-direction) & $10 \mathrm{~mm}$ \\
\hline$f_{f}$ (front fraction) & 1.55 \\
\hline$f_{r}$ (rear fraction) & 0.45 \\
\hline Welding speed, $v$ & $7.50 \mathrm{~mm} / \mathrm{s}$ \\
\hline Welding voltage, $U$ & $25 \mathrm{~V}$ \\
\hline Welding current, $I$ & $450 \mathrm{~A}$ \\
\hline Welding efficiency, $\eta$ & 0.8 \\
\hline Heat input, $Q=\eta I U$ & $9000 \mathrm{~W}$ \\
\hline Heat input, $Q_{j}=\eta I U / v$ & $1.2 \mathrm{KJ} / \mathrm{mm}$ \\
\hline
\end{tabular}


Table 2. Thermo-physical and thermo-mechanical properties of A36 [16].

\begin{tabular}{|c|c|c|c|c|c|c|}
\hline $\begin{array}{c}\text { Temperature } \\
\left({ }^{\circ} \mathbf{C}\right)\end{array}$ & $\begin{array}{c}\text { Density } \\
\left(\mathbf{k g} / \mathbf{m}^{\mathbf{3}}\right)\end{array}$ & $\begin{array}{c}\text { Specific } \\
\mathbf{H e a t} \\
\left(\mathbf{J} / \mathbf{k g} /{ }^{\circ} \mathbf{C}\right)\end{array}$ & $\begin{array}{c}\text { Conductivity } \\
\left(\mathbf{W} / \mathbf{m} /{ }^{\circ} \mathbf{C}\right)\end{array}$ & $\begin{array}{c}\text { Young's } \\
\text { Modulus } \\
\left(\mathbf{1 0}^{\mathbf{9}} \mathbf{P a}\right)\end{array}$ & $\begin{array}{c}\text { Poisson } \\
\text { Ratio }\end{array}$ & $\begin{array}{c}\text { Thermal } \\
\text { Expansion } \\
\mathbf{C o e f f} . \\
\left(\mathbf{1 0}^{-\mathbf{7}} /{ }^{\circ} \mathbf{C}\right)\end{array}$ \\
\hline 0 & 7900 & 444 & 45.9 & 205 & 0.33 & 120 \\
\hline 100 & 7880 & 472 & 44.8 & 202.5 & 0.34 & 122 \\
\hline 200 & 7830 & 503 & 43.4 & 200 & 0.35 & 124 \\
\hline 300 & 7790 & 537 & 41.4 & 187.5 & 0.36 & 126 \\
\hline 400 & 7750 & 579 & 38.9 & 175 & 0.37 & 128 \\
\hline 600 & 7660 & 692 & 33.6 & 148 & 0.39 & 132 \\
\hline 800 & 7560 & 837 & 28.7 & 100 & 0.41 & 136 \\
\hline 1200 & 7370 & 860 & 28.6 & 17.5 & 0.45 & 144 \\
\hline 1300 & 7320 & 863 & 29.5 & 15 & 0.46 & 146 \\
\hline 1500 & 7320 & - & - & 10 & 0.48 & 150 \\
\hline
\end{tabular}

Table 3. Composition of A36 steel.

\begin{tabular}{|c|c|c|c|c|c|c|}
\hline Carbon & Copper & Iron & Manganese & Phosphorus & Silicon & Sulfur \\
\hline $0.25-$ & $0.2 \%$ & 98 & $1.03 \%$ & $0.04 \%$ & $0.28 \%$ & 0.05 \\
$0.29 \%$ & & $\%$ & & & & $\%$ \\
\hline
\end{tabular}

The problem was solved in the transient structural module of ANSYS software. The problem domain has 28505 nodes and 5000 elements; the transient analysis was performed in 0.02 -second increments. One hundred twenty seconds' hard-facing process solution takes 17 hours, one hundred and eighty seconds' hard-facing process takes 26 hours. The computer used in the process has an Intel I7 CPU and 16 GB of RAM. Grey relational analysis was used to minimize the computing effort.

As for the boundary conditions; the structural boundary conditions for the hard-facing process are as follows: The four corners of the welded plate which are lines in the z-direction are kept fixed (see Figure 2d). The Goldak double ellipsoidal parameters for the hard-facing process are tabulated in Table 4 . The thermal boundary conditions are as follows. Ambient temperature was taken at $20^{\circ} \mathrm{C}$, the convective heat transfer coefficient and emissivity were chosen as $6 \mathrm{~W} / \mathrm{m}^{2} /{ }^{\circ} \mathrm{C}$ and 0.9 .

Table 4. The Goldak double ellipsoidal parameters for the hard-facing process.

\begin{tabular}{|c|c|}
\hline$a$ (parameter in x-direction) & $5 \mathrm{~mm}$ \\
\hline$b_{f}$ (parameter in y-direction, front) & $5 \mathrm{~mm}$ \\
\hline$b_{r}$ (parameter in y-direction, rear) & $8 \mathrm{~mm}$ \\
\hline$c$ (parameter in z-direction) & $5 \mathrm{~mm}$ \\
\hline$f_{f}$ (front fraction) & 0.5 \\
\hline$f_{r}$ (rear fraction) & 1.5 \\
\hline Welding speed, $v$ & $10.0 \mathrm{~mm} / \mathrm{s}$ \\
\hline Welding voltage, $U$ & $40 \mathrm{~V}$ \\
\hline Welding current, $I$ & $150 \mathrm{~A}$ \\
\hline Welding efficiency, $\eta$ & 0.83 \\
\hline Heat input, $Q=\eta I U$ & $5000 \mathrm{~W}$ \\
\hline Heat input, $Q_{j}=\eta I U / \mathrm{v}$ & $0.5 \mathrm{KJ} / \mathrm{mm}$ \\
\hline
\end{tabular}


In Table 5, one can see the eight simulations investigated in this work. By performing these eight numerical simulations, one can choose the optimum welding conditions to minimize the residual stresses and deformations.

Table 5. The simulation details.

\begin{tabular}{|l|l|l|l|l|}
\hline $\begin{array}{l}\text { Simulation No. } \\
\text { (Abbreviated } \\
\text { as SIM) }\end{array}$ & $\begin{array}{l}\text { Welding Speed } \\
(\mathbf{m m} / \mathbf{s})\end{array}$ & $\begin{array}{c}\text { Welding } \\
\text { Current }(\mathbf{A})\end{array}$ & $\begin{array}{l}\text { Heat Input } \\
(\mathbf{K J} / \mathbf{m m}), \boldsymbol{Q}_{j}\end{array}$ & Pattern \\
\hline 1 & 10 & 150 & 0.5 & Straight \\
\hline 2 & 10 & 150 & 0.5 & Reverse \\
\hline 3 & 10 & 200 & 0.66 & Straight \\
\hline 4 & 10 & 200 & 0.66 & Reverse \\
\hline 5 & 15 & 150 & 0.33 & Straight \\
\hline 6 & 15 & 150 & 0.33 & Reverse \\
\hline 7 & 15 & 200 & 0.44 & Straight \\
\hline 8 & 15 & 200 & 0.44 & Reverse \\
\hline
\end{tabular}

The validation of the numerical solution was established by experiment 1 found in Ref. [24]. The model and the experiment have the same welding conditions, material, and geometry. The peak temperature in the middle point of path 1 (see Figure $2 \mathrm{c}$ ) is $334{ }^{\circ} \mathrm{C}$ for the present model and $320^{\circ} \mathrm{C}$ for experiment 1 from Ref. [24]. The error is not more than 5 percent, which is very acceptable. The total deformation UT (The maximum contribution of total deformation is from the - (minus) z-direction and on the bottom surface and in the middle of the weld centerline.) calculated by the present model is $2.65 \mathrm{~mm}$, whereas the experimental measurement from Ref. [24] was $2.67 \mathrm{~mm}$. These comparisons show that the model's thermal and structural parts can be utilised to predict the residual stresses during the hard-facing application presented in this work.

\section{Grey relational analysis}

Grey relational analysis is utilised to minimize the deformations and the residual stresses in the hard-facing process simulations. The following equations should be used to minimize the responses, and we start with normalization:

$$
x_{i}^{*}(k)=\frac{\max x_{i}(k)-x_{i}(k)}{\max x_{i}(k)-\min x_{i}(k)}
$$

where, $\mathrm{i}=1, \ldots, \mathrm{m} ; \mathrm{k}=1, \ldots, \mathrm{n}, \mathrm{m}$ is the number of simulation data, and $\mathrm{n}$ is the number of responses. $x_{i}(k)$ denotes the original sequence, $x_{i}{ }^{*}(k)$ denotes the sequence after the data processing, max $x_{i}(k)$, and $\min x_{i}(k)$ values are the largest and smallest values of $x_{i}(k)$.

The next step is the calculation of grey relational coefficient $\xi_{\mathrm{i}}(\mathrm{k})$ from the normalized values from the following equations:

$$
\begin{aligned}
\Delta_{o i}(k) & =\left\|x_{0}(k)-x_{i}(k)\right\| \\
\xi_{i}(k) & =\frac{\Delta_{\min }+\zeta \Delta_{\max }}{\Delta_{o i}(k)+\zeta \Delta_{\max }}
\end{aligned}
$$

where, $\mathrm{x}_{0}(\mathrm{k})$ implies the reference sequence, $\mathrm{xi}(\mathrm{k})$ is the comparability sequence, and $\Delta_{o i}(k)$ is the deviation sequence. $\Delta_{\min }$ and $\Delta_{\max }$ are the minimum and the maximum values of the absolute differences $\left(\Delta_{o i}\right)$ of all comparing sequences. $\zeta$ value is usually taken as 0.5 . 
The following equation can compute grey relational grade (GRG):

$$
\gamma_{i}=\frac{1}{n} \sum_{k=1}^{n} \xi_{i}(k)
$$

where, $\gamma_{i}$ is the required grey relational grade for the ith simulation, and $\mathrm{n}$ is the number of response characteristics ( 3 for our case). The highest value of GRG is the optimum solution to the multi-objective optimization problem [37].

\section{Results and Discussion}

Temperature distributions for simulations 1 and 6 can be seen in Figures $3 a$ and $3 b$. The lower welding speed causes a higher temperature in the straight pattern. In the reverse pattern, the welding speed was increased by $50 \%$ resulting in a considerable decline in temperature. By looking at these two figures, one can understand that heat input is substantially affected by the welding speed. The longitudinal stress distribution for simulation 1 at 100 seconds can be seen in Figure 3c. The maximum tensile stress is 1.43 times the yield strength (YS) of the material used. The compressive stresses surpassing the ultimate tensile strength (UTS) can be explained that the sharp fixed supports at the corners of the plates. One cell away from the sharp corners have compressive stresses below the UTS. One thing that should be made clear is that the deformations depicted in these figures are magnified by 4 .

Figure 4 shows the transverse residual stresses along path 2, depicted in Figure 2c. From SIM1 to SIM8 the results are shown for the $180^{\text {th }}$ second, which is the end of the hard-facing process. SIM1* shows the residual stress 720 seconds from the beginning of the process. One should analyze this figure in groups of two. Simulations 3 and 4 produce the highest transverse stress, simulations 7 and 8 follow this group. Simulations 5 and 6 produce the lowest transverse stress. In between the last two groups, simulations 1 and 2 take place. The ordering of these simulations according to their transverse stress values on path 2 follows mainly their heat input values in Table 5. One contradiction to this thesis is that simulations 7 and 8 come before simulations 1 and 2 although their heat input value $(0.44 \mathrm{KJ} / \mathrm{mm})$ is lower than the other group $(0.5 \mathrm{KJ} / \mathrm{mm})$. This fact can be explained by the welding current value. In simulations 7 and 8, the welding current value is $200 \mathrm{~A}$ which is greater than the other group. When one investigates the influence of the welding pattern in Figure 4, one can see that in the first half of the path the straight patterns always produce higher stresses than the reverse patterns. In the second half of the path, one can observe vice versa. This can be explained by the delayed cooling effect of the welding patterns. After 9 minutes of cooling time, the transverse stress gets higher at the beginning and end of the path. This can be explained by the contraction caused by the cooling. The fixed supports are close to the beginning and end of the path. This fact may also be important for this result. 

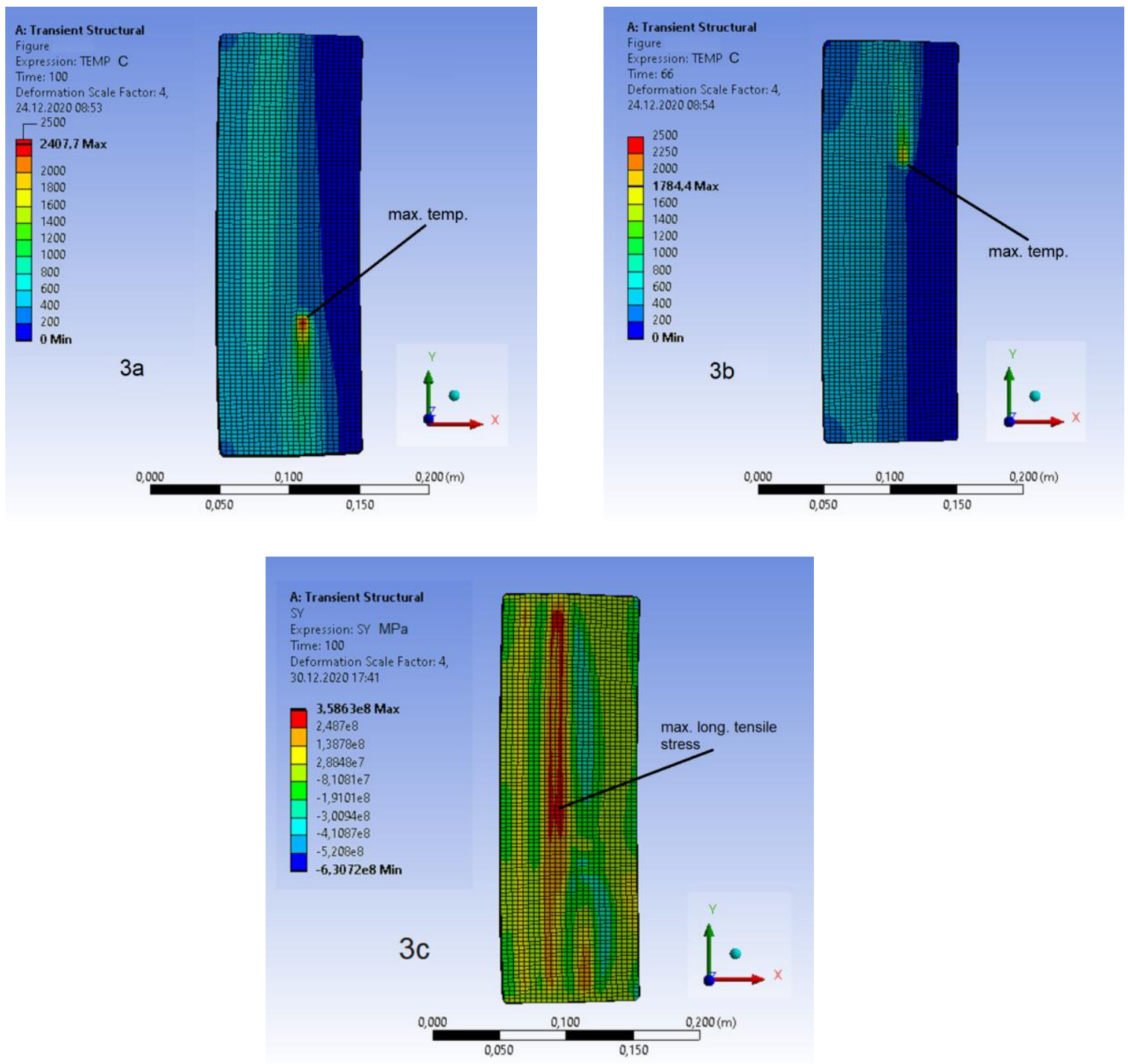

Figure 3. Temperature distributions. a. Simulation 1, temperature distribution at 100th second, b. Simulation 6, temperature distribution at 66th second, c. Simulation 1, longitudinal stress distribution at 100 th second.

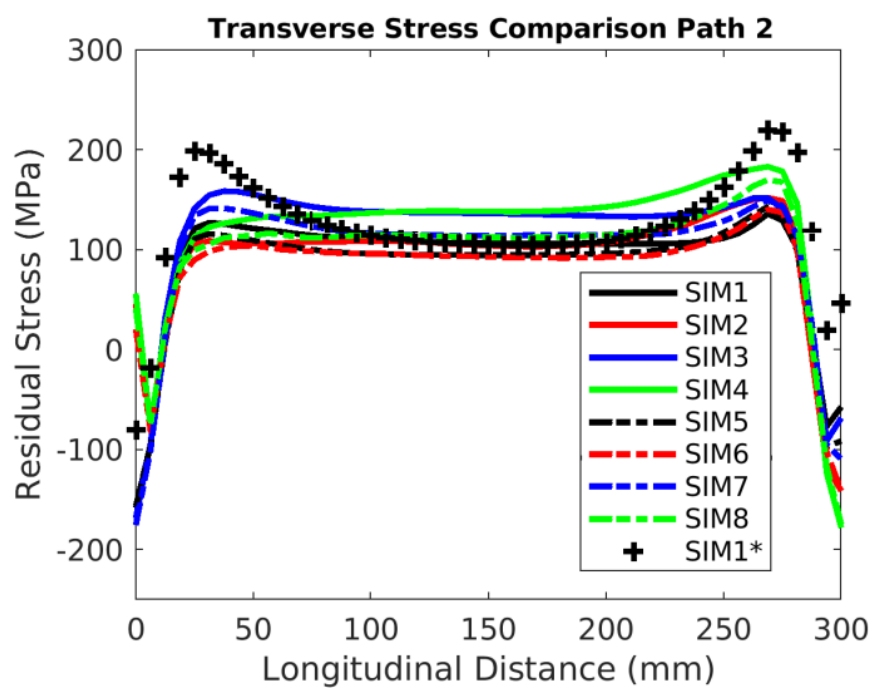

Figure 4. Transverse residual stresses along path 2. 
Figure 5 depicts the longitudinal residual stresses along path 1. Except for SIM1* the results are shown for the $180^{\text {th }}$ second. Here, reverse patterns (red and green lines in the figure) produce lower stresses in the first half of the path. When one looks at the second half of the path, one can see that straight patterns (black and blue lines in the figure) cause lower stresses. This can be explained by the delayed cooling effect caused by the type of pattern. The highest stress can be encountered in the first half of the path with simulation 1, whereas the lowest one comes from simulation 3. In the second half of the path, the highest stress was observed in simulation 2 and the lowest stress was seen in simulation 4 . The cooling effect was investigated in SIM1*, which gives the $720^{\text {th }}$ second of the process. The residual stress is not affected in between $120^{\text {th }}$ and $180^{\text {th }} \mathrm{mm} . \mathrm{s}$ of the path. This can be explained by the fact that the fixed supports are away from the investigated part of the path. That is why the cooling contractions may not prevail.

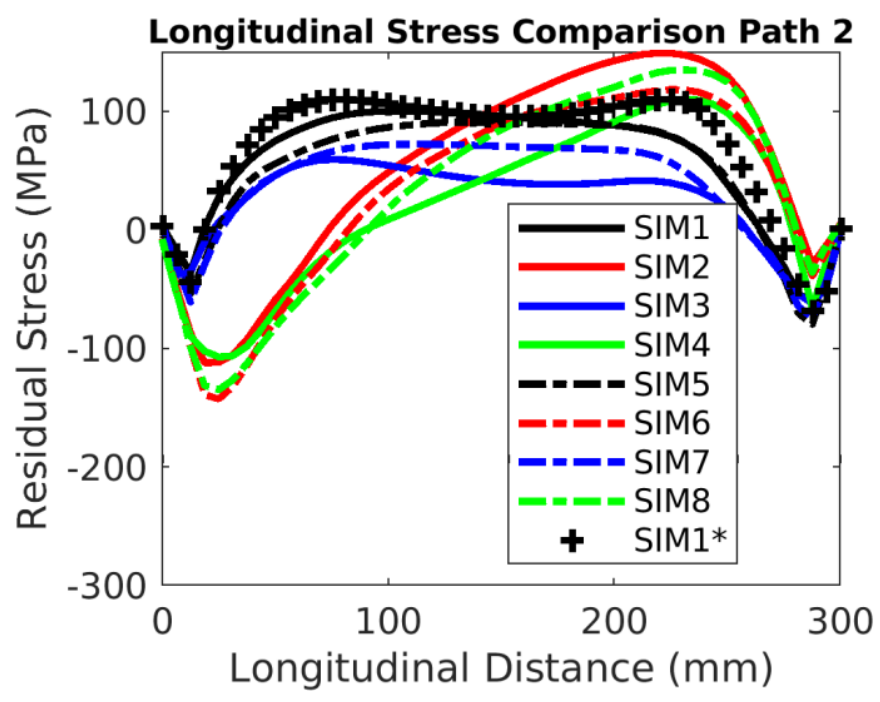

Figure 5. Longitudinal residual stresses along path 2.

Figure 6 shows the total deformation along path 2. The deformations can be ordered from the highest to the lowest according to the heat input values of the simulations. Simulations 3 and 4 have the highest heat input $(0.66 \mathrm{KJ} / \mathrm{mm})$ and the highest deformation. Since the fixed supports are on the corners of the plate, it is quite normal to have the maximum deformation in the middle of the plate. The lowest heat input $(0.33 \mathrm{KJ} / \mathrm{mm})$ produces the minimum deformation (dotted black and red lines). As for the lines in between the two extrema, one can say that although the heat inputs are different from each other, they produce the same amount of deformation. Simulations 7 and 8 have $(0.44 \mathrm{KJ} / \mathrm{mm})$, whereas simulations 1 and 2 have $(0.5 \mathrm{KJ} / \mathrm{mm})$. In simulations 7 and 8 the welding current is greater than the one in simulations 1 and 2. This can explain why they produce the same amount of deformation. When one observes the two extrema again, one can say that the reverse pattern causes a deformation slightly greater than the other pattern. The cooling period does not affect the total deformation much.

Figure $7 \mathrm{a}$ shows the temperature distribution at the $720^{\text {th }}$ second. The maximum temperature went down to $644 \mathrm{C}$. Reaching the ambient temperature could not be achieved because of the restricted computer resources. Figure $7 \mathrm{~b}$ gives the longitudinal stress distribution at the $720^{\text {th }}$ second after 9 minutes of cooling. Since the fixed supports are very sharp, the higher stress values must not be considered near the fixed supports. The stress values along the welding paths are around $300 \mathrm{Mpa}$, which is very reasonable. 


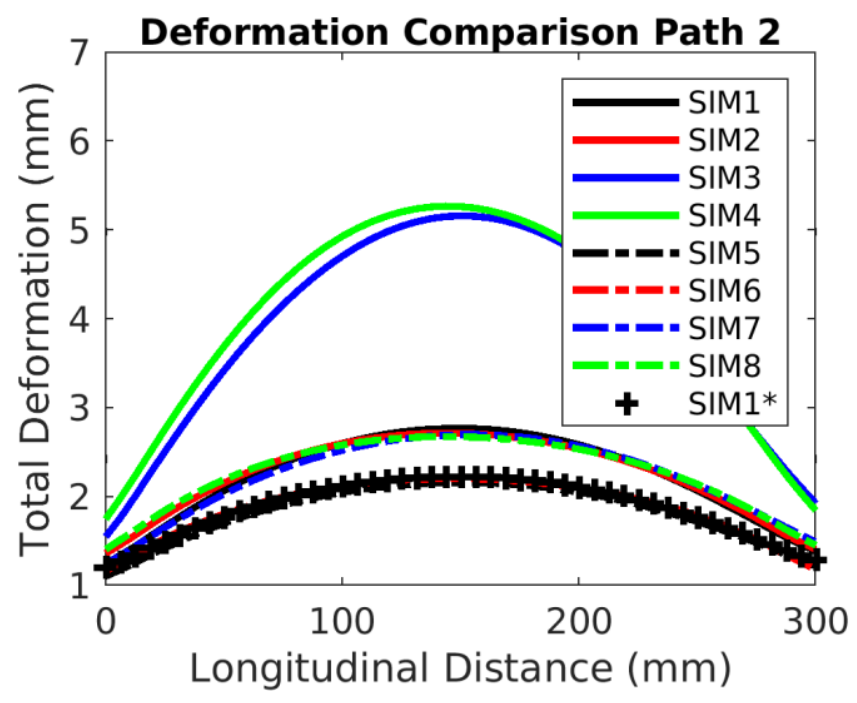

Figure 6. Total deformation along path 2 .

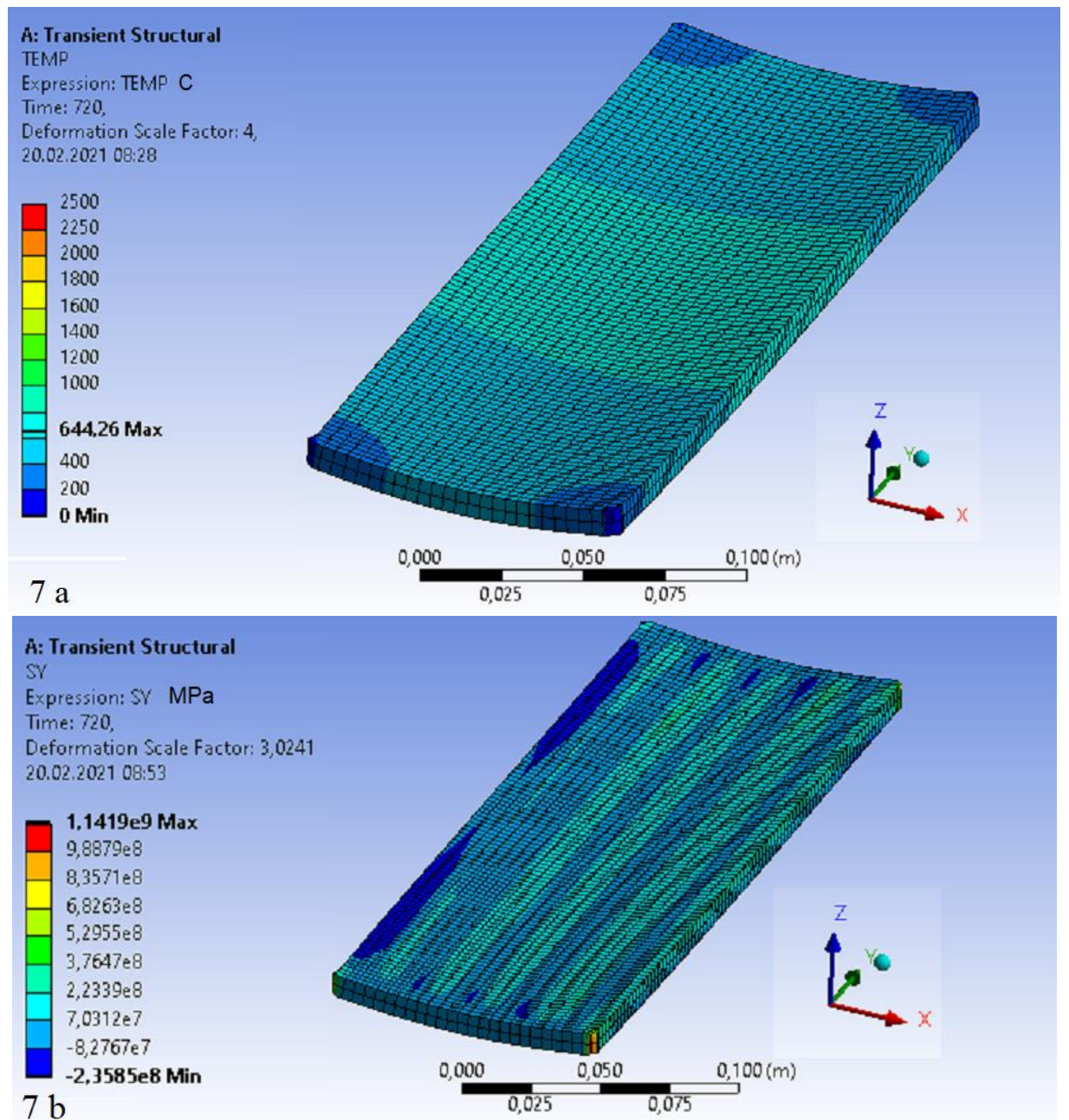

Figure 7. a. Temperature and longitudinal stress distributions after 720 seconds (SIM1) a. temperature distribution b. longitudinal stress distribution. 
To apply the grey relational analysis to the simulations' results, the transverse and longitudinal residual stresses, and deformations along paths 2 should be analyzed. These values can be seen in Table 6 .

Table 6. The numerical simulation results (along paths 2 (see Figure $2 \mathrm{c}$ )). These values are obtained at the end of the hard-facing process, i.e in the 180th second and 120th second.

\begin{tabular}{|l|l|l|l|l|l|l|l|l|}
\hline $\begin{array}{c}\text { Simulation } \\
\begin{array}{c}\text { No. } \\
\text { (Abbreviated } \\
\text { as SIM) }\end{array}\end{array}$ & \multicolumn{3}{|c|}{$\begin{array}{l}\text { Transverse } \\
\text { Max. }\end{array}$} & \multicolumn{2}{|c|}{$\begin{array}{l}\text { Max. } \\
\text { Residual Stress (MPa) } \\
\text { Residual Stress (MPa) }\end{array}$} & $\begin{array}{l}\text { Longitudinal } \\
\text { Defor- } \\
\text { mation } \\
\text { (mm) }\end{array}$ & $\begin{array}{l}\text { Time for } \\
\text { data } \\
\text { collection } \\
\text { (s) }\end{array}$ \\
\hline- & SX & SX/YS & SX/UTS & SY & SY/YS & SY/UTS & - & - \\
\hline 1 & 136.1 & 0.5444 & 0.2722 & 100.6 & 0.4024 & 0.2012 & 2.77 & 180 \\
\hline 2 & 152.1 & 0.6084 & 0.3042 & 149.3 & 0.5972 & 0.2986 & 2.71 & 180 \\
\hline 3 & 158.7 & 0.6348 & 0.3174 & 59.6 & 0.2384 & 0.1192 & 5.16 & 180 \\
\hline 4 & 183.2 & 0.7328 & 0.3664 & 110.8 & 0.4432 & 0.2216 & 5.27 & 180 \\
\hline 5 & 143.1 & 0.5724 & 0.2862 & 91.2 & 0.3648 & 0.1824 & 2.16 & 120 \\
\hline 6 & 140.3 & 0.5612 & 0.2806 & 118.6 & 0.4744 & 0.2372 & 2.2 & 120 \\
\hline 7 & 149.5 & 0.598 & 0.299 & 72.5 & 0.29 & 0.145 & 2.7 & 120 \\
\hline 8 & 170.0 & 0.68 & 0.34 & 135.2 & 0.5408 & 0.2704 & 2.68 & 120 \\
\hline
\end{tabular}

The welding parameters' influence for both residual stresses and deformations can be seen in Table 7 and Figure 7. The highest grey relational grade gives the optimum solution. The optimum solution is simulation 5 which has the lowest heat input and straight pattern. On the other hand, simulation 4 gives the worst solution to the optimization problem. It has the highest heat input and reverse pattern. When one investigates the straight patterns (simulations 1, 3, 5, and 7), it is observed that they always produce better results than the reverse patterns $(2,4,6$, and 8$)$, when the other parameters are kept constant.

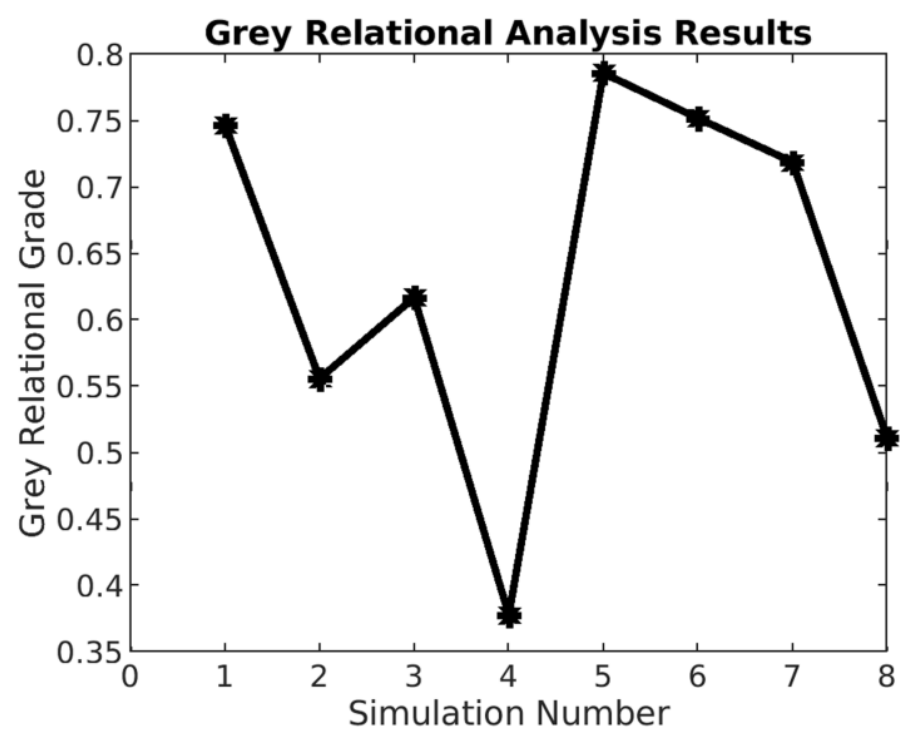

Figure 8. Gray Relational Analysis for minimizing both residual stresses and total deformations. 
Table 7. Grey relational analysis results for path 2 , normalization (Eq.(4)), deviation sequence (Eq.(5)), grey relational coefficient (GRC) (Eq.(6)) and grey relational grade (GRG) (Eq.(7)) calculations. The maximum residual stresses and maximum total deformation values are taken from Table 6.

\begin{tabular}{|c|c|c|c|c|c|c|c|c|c|c|}
\hline & \multicolumn{3}{|c|}{ Normalization } & \multicolumn{3}{|c|}{ Deviation Sequence } & \multicolumn{3}{|c|}{ GRC } & GRG \\
\hline & $\begin{array}{l}\text { Max. } \\
\text { Stress } \\
\text { SX } \\
(\mathrm{MPa})\end{array}$ & $\begin{array}{l}\text { Max. } \\
\text { Stress } \\
\text { SY } \\
(\mathrm{MPa})\end{array}$ & $\begin{array}{l}\text { Max. } \\
\text { Defor- } \\
\text { mation } \\
(\mathrm{mm})\end{array}$ & $\begin{array}{l}\text { Max. } \\
\text { Stress } \\
\text { SX } \\
(\mathrm{MPa})\end{array}$ & $\begin{array}{l}\text { Max. } \\
\text { Stress } \\
\text { SY } \\
(\mathrm{MPa})\end{array}$ & $\begin{array}{l}\text { Max. } \\
\text { Defor- } \\
\text { mation } \\
(\mathrm{mm})\end{array}$ & $\begin{array}{l}\text { Max. } \\
\text { Stress } \\
\text { SX } \\
(\mathrm{MPa})\end{array}$ & $\begin{array}{l}\text { Max. } \\
\text { Stress } \\
\text { SY } \\
(\mathrm{MPa})\end{array}$ & $\begin{array}{l}\text { Max. } \\
\text { Defor- } \\
\text { mation } \\
(\mathrm{mm})\end{array}$ & - \\
\hline $\begin{array}{l}\text { SIM } \\
1\end{array}$ & 1.000 & 0.543 & 0.804 & 0.000 & 0.457 & 0.196 & 1.000 & 0.522 & 0.718 & 0.747 \\
\hline $\begin{array}{l}\text { SIM } \\
2\end{array}$ & 0.660 & 0.000 & 0.823 & 0.340 & 1.000 & 0.177 & 0.595 & 0.333 & 0.739 & 0.556 \\
\hline $\begin{array}{l}\text { SIM } \\
3\end{array}$ & 0.520 & 1.000 & 0.035 & 0.480 & 0.000 & 0.965 & 0.510 & 1.000 & 0.341 & 0.617 \\
\hline $\begin{array}{l}\text { SIM } \\
4\end{array}$ & 0.000 & 0.429 & 0.000 & 1.000 & 0.571 & 1.000 & 0.333 & 0.467 & 0.333 & 0.378 \\
\hline $\begin{array}{l}\text { SIM } \\
5\end{array}$ & 0.851 & 0.648 & 1.000 & 0.149 & 0.352 & 0.000 & 0.771 & 0.587 & 1.000 & 0.786 \\
\hline $\begin{array}{l}\text { SIM } \\
6\end{array}$ & 0.911 & 0.342 & 0.987 & 0.089 & 0.658 & 0.013 & 0.849 & 0.432 & 0.975 & 0.752 \\
\hline $\begin{array}{l}\text { SIM } \\
7\end{array}$ & 0.715 & 0.856 & 0.826 & 0.285 & 0.144 & 0.174 & 0.637 & 0.777 & 0.742 & 0.719 \\
\hline $\begin{array}{l}\text { SIM } \\
8\end{array}$ & 0.280 & 0.157 & 0.833 & 0.720 & 0.843 & 0.167 & 0.410 & 0.372 & 0.749 & 0.511 \\
\hline
\end{tabular}

The validation of the results was performed by a welding experiment, the results of which are given in Figures $9 \mathrm{a}$ and $9 \mathrm{~b}$. The welding conditions are taken from simulation 1, i.e the welding speed is $10 \mathrm{~mm} / \mathrm{s}$, the welding current is $150 \mathrm{~A}$, voltage is $40 \mathrm{~V}$, and the type of pattern is straight. Argon gas is utilized for shielding the weld pool. The maximum deformation obtained from the simulation is $2.77 \mathrm{~mm}$. The experimental deformation measurement gives a value of $3 \mathrm{~mm}$. One can say that the results of the 8 simulations can be reliable and can be used by the welding engineers who want to perform hard-facing with mild steel. In Figures $9 a$ and $9 b$, it is obvious that the deformation is in the - (minus) z-direction, and this deformation causes a concave structure in the plate. 


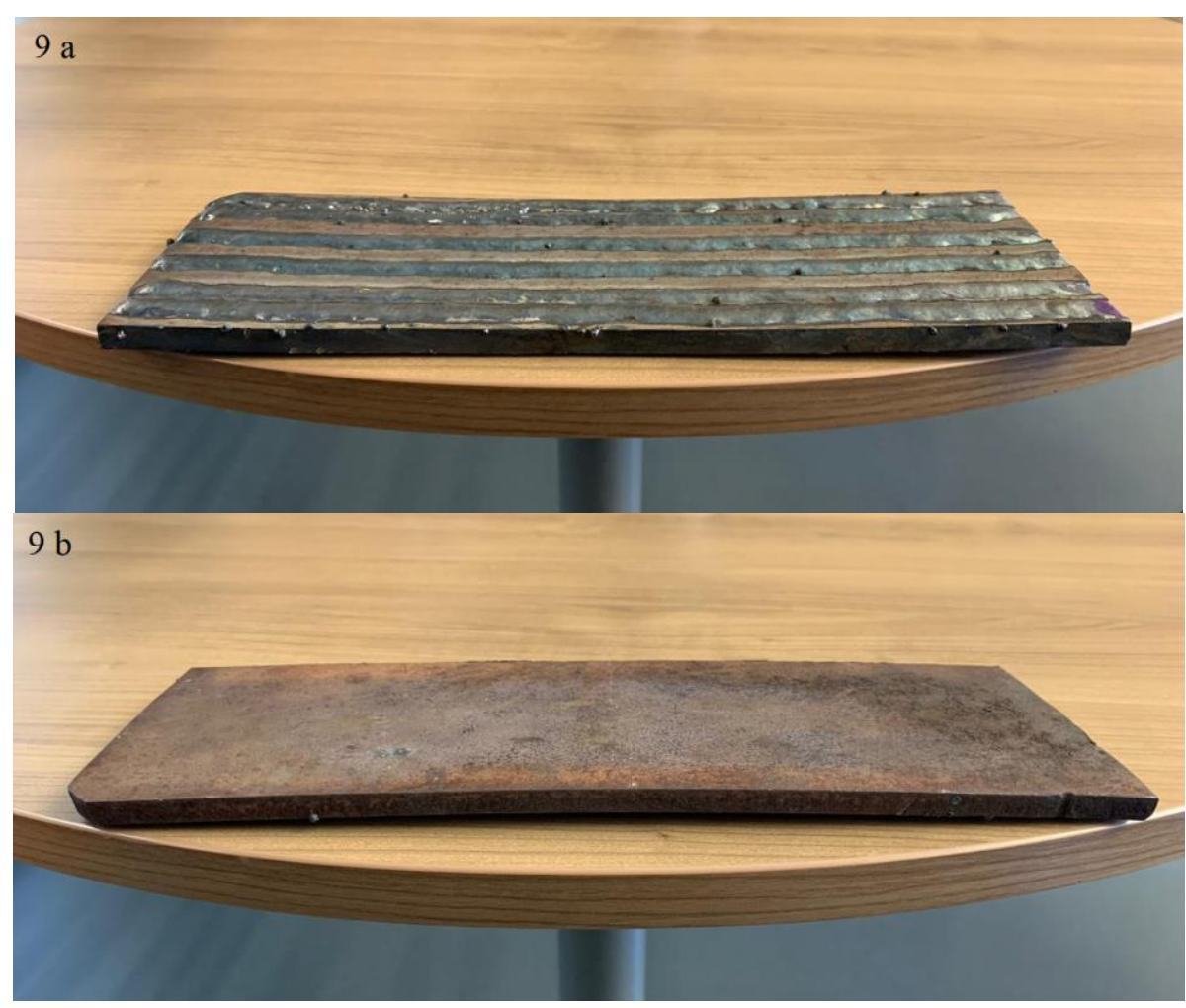

Figure 9. a. Hard-faced plate (SIM1) a. upper surface b. bottom surface

\section{Conclusion}

Modeling efforts for hard-facing processes can not be encountered much in the literature. In this present work, the finite element method (FEM), together with the statistical method grey relational analysis, was utilised to minimize the transverse and longitudinal residual stresses and deformations. The FEM part was structured with two-way coupling between the thermal and structural parts. Coupling between the two parts was performed using temperature-dependent material properties such as thermal expansion coefficient, elasticity modulus, and Poisson's ratio. Since the time-dependent simulations took so much time, the number of simulations is kept as low as possible. The cooling effect was also investigated and the influence of cooling on the residual stresses and deformations was reported.

One can conclude that for mild steel's hard-facing:

- One should use lower heat input to minimize residual stresses and deformations.

- The type of pattern should be chosen as the straight pattern for minimization of the residual stresses and deformations.

- In general transverse residual stresses in eight simulations were ordered according to their heat input along path 2 (the path located in the middle of the transverse direction on top of the plate). The maximum heat input gave the maximum transverse stress.

- Longitudinal residual stresses along path 2 behave according to their type of welding pattern.

- Deformations along path 2 are mainly affected by the heat input.

- The cooling period has much more influence on the transverse stress rather than the longitudinal stress.

- Transverse stress at the beginning and end of path 2 gets higher significantly after cooling

- Cooling does not affect the total deformation. 
- The high stresses near the sharp fixed supports should not be considered. They may mislead the researcher.

Supplementary Materials: The datasets generated during the current study are available from the corresponding author on a reasonable request.

Funding: This research received no external funding

Conflicts of Interest: The author declares no conflict of interest.

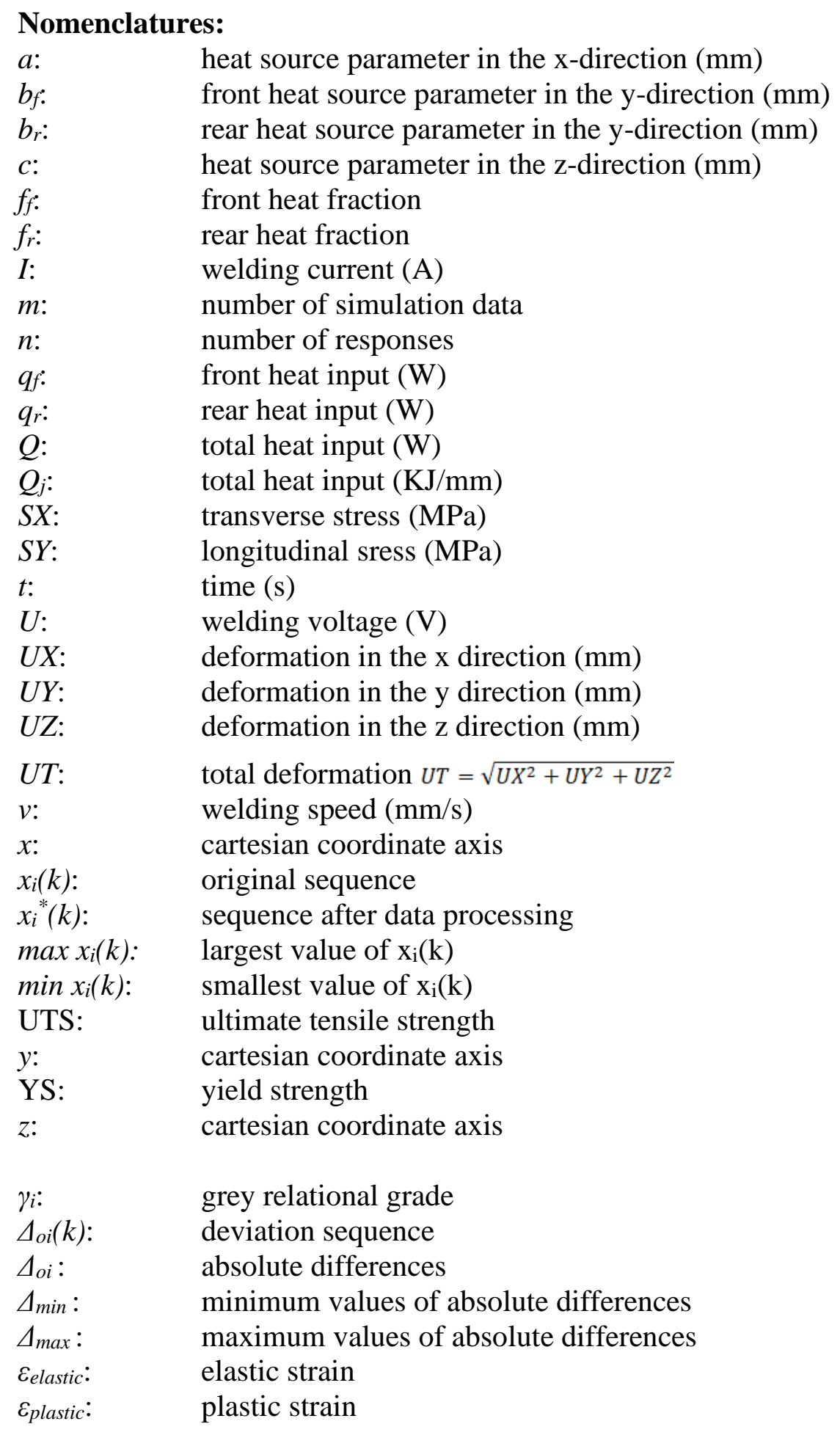




$\begin{array}{ll}\varepsilon_{\text {thermal }:} & \text { thermal strain } \\ \varepsilon_{\text {total }:} & \text { total strain } \\ \zeta: & \text { coefficient taken as } 0.5 \\ \eta: & \text { welding efficiency } \\ \xi_{i}(k): & \text { grey relational coefficient } \\ \sigma_{x x}: & \text { transverse residual stress }(\mathrm{MPa}) \\ \sigma_{y y}: & \text { longitudinal residual stress }(\mathrm{MPa}) \\ \tau: & \text { lag factor }(\mathrm{s})\end{array}$

\section{References}

[1] J. Goldak, A. Chakravarti, and M. Bibby, "A New Finite Element Model for Welding Heat Sources," Met. Trans. B, vol. 15 B, p. 299, 1984, https://doi.org/10.1080/21681805.2017.1363816

[2] D. Gery, H. Long, and P. Maropoulos, "Effects of welding speed, energy input and heat source distribution on temperature variations in butt joint welding," J. Mater. Process. Technol., vol. 167, no. 2-3, pp. 393-401, 2005, https://doi.org/10.1016/j.jmatprotec.2005.06.018

[3] A. Ghosh and S. Chattopadhyaya, "Conical Gaussian Heat Distribution For Submerged Arc Welding Process," Int. J. Mech. Eng. Technol., vol. 1, no. 1, pp. 109-123, 2010, [Online]. Available: http://www.iaeme.com/ijmet.html.

[4] M. J. Attarha and I. Sattari-Far, "Study on welding temperature distribution in thin welded plates through experimental measurements and finite element simulation," J. Mater. Process. Technol., vol. 211, no. 4, pp. 688-694, Apr. 2011, https://doi.org/10.1016/j.jmatprotec.2010.12.003

[5] A. Ghosh and H. Chattopadhyay, "Mathematical modeling of moving heat source shape for submerged arc welding process," Int. J. Adv. Manuf. Technol., vol. 69, no. 9-12, pp. 2691-2701, 2013, https://doi.org/10.1007/s00170-013-5154-Z

[6] V. García-García, J. C. Camacho-Arriaga, and F. Reyes-Calderón, "A simplified elliptic paraboloid heat source model for autogenous GTAW process," Int. J. Heat Mass Transf., vol. 100, pp. 536-549, Sep. 2016, https://doi.org/10.1016/j.ijheatmasstransfer.2016.04.064

[7] V. Chandelkar and S. K. Pradhan, "Numerical simulation of temperature distribution and experimentation in laser beam welding of SS317L alloy," Mater. Today Proc., Jan. 2020, https://doi.org/10.1016/j.matpr.2019.11.331

[8] I. F. Z. Fanous, M. Y. A. Younan, and A. S. Wifi, "3-D finite element modeling of the welding process using element birth and element movement techniques," J. Press. Vessel Technol. Trans. ASME, vol. 125, no. 2, pp. 144-150, 2003, https://doi.org/10.1115/1.1564070

[9] D. Deng, H. Murakawa, and W. Liang, "Numerical simulation of welding distortion in large structures," Comput. Methods Appl. Mech. Eng., vol. 196, no. 45-48, pp. 4613-4627, Sep. 2007, https://doi.org/10.1016/j.cma.2007.05.023

[10] V. Deaconu, "Finite Element Modelling of Residual Stress - A Powerful Tool in the Aid of Structural Integrity Assessment of Welded Structures Microstructure Heat flow Mechanics," ISCS - Struct. Integr. Welded Struct., pp. 20-21, 2007, [Online]. Available: www.ndt.net/search/docs.php3?MainSource=56.

[11] D. Stamenkovic and I. Vasovic, "Finite Element Analysis of Residual Stress in Butt Welding Two Similar Plates," Sci. Tech. Rev., vol. 59, no. 1, pp. 57-60, 2009.

[12] M. Jeyakumar, T. Christopher, R. Narayanan, and B. Nageswara Rao, "Residual stress evaluation in butt-welded steel plates," Indian J. Eng. Mater. Sci., vol. 18, no. 6, pp. 425-434, 2011.

[13] M. Jeyakumar, T. Christopher, R. Narayanan, and B. Nageswara, "Residual Stress Evaluation in Buttwelded IN718 Plates," Can. J. Basic Appl. Sci., vol. 02, no. 02, pp. 88-99, 2013.

[14] A. Ravisankar, S. K. Velaga, G. Rajput, and S. Venugopal, "Influence of welding speed and power on residual stress during gas tungsten arc welding (GTAW) of thin sections with constant heat input: A study using numerical simulation and experimental validation," J. Manuf. Process., vol. 16, no. 2, pp. 200-211, 2014, https://doi.org/10.1016/j.jmapro.2013.11.002

[15] D. B. Darmadi, A. Kiet-Tieu, and J. Norrish, "A validated thermo mechanical FEM model of bead-onplate welding," in International Journal of Materials and Product Technology, 2014, vol. 48, no. 1-4, pp. 146-166, https://doi.org/10.1504/IJMPT.2014.059047

[16] B. Q. Chen, M. Hashemzadeh, and C. Guedes Soares, "Numerical and experimental studies on temperature and distortion patterns in butt-welded plates," Int. J. Adv. Manuf. Technol., vol. 72, no. 5-8, 


\section{pp. 1121-1131, 2014, https://doi.org/10.1007/s00170-014-5740-8}

[17] M. R. Nezamdost, M. R. N. Esfahani, S. H. Hashemi, and S. A. Mirbozorgi, "Investigation of temperature and residual stresses field of submerged arc welding by finite element method and experiments," Int. J. Adv. Manuf. Technol., vol. 87, no. 1-4, pp. 615-624, 2016, https://doi.org/10.1007/s00170-016-8509-4

[18] V. M. Varma Prasad, V. M. Joy Varghese, M. R. Suresh, and D. Siva Kumar, "3D Simulation of Residual Stress Developed During TIG Welding of Stainless Steel Pipes," Procedia Technol., vol. 24, pp. 364-371, 2016, https://doi.org/10.1016/j.protcy.2016.05.049

[19] D. F. Almeida, R. F. Martins, and J. B. Cardoso, "Numerical simulation of residual stresses induced by TIG butt-welding of thin plates made of AISI 316L stainless steel," in Procedia Structural Integrity, 2017, vol. 5, pp. 633-639, https://doi.org/10.1016/i.prostr.2017.07.032

[20] D. Venkatkumar, D. Ravindran, and G. Selvakumar, "Finite Element Analysis of Heat Input Effect on Temperature, Residual Stresses and Distortion in Butt Welded Plates," in Materials Today: Proceedings, 2018, vol. 5, no. 2, pp. 8328-8337, https://doi.org/10.1016/j.matpr.2017.11.525

[21] M. Arunkumar, V. Dhinakaran, and N. Siva Shanmugam, "Numerical prediction of temperature distribution and residual stresses on plasma arc welded thin titanium sheets," Int. J. Model. Simul., pp. 117, Dec. 2019, https://doi.org/10.1080/02286203.2019.1700089

[22] Y. Balram and G. Rajyalakshmi, "Thermal fields and residual stresses analysis in TIG weldments of SS 316 and Monel 400 by numerical simulation and experimentation," Mater. Res. Express, vol. 6, no. 8, Jun. 2019, https://doi.org/10.1088/2053-1591/ab23cf

[23] A. S. Ahmad, Y. Wu, H. Gong, and L. Nie, "Finite element prediction of residual stress and deformation induced by double-pass TIG welding of Al 2219 plate," Materials (Basel)., vol. 12, no. 14, 2019, https://doi.org/10.3390/ma12142251

[24] H. Arora, R. Singh, and G. S. Brar, "Prediction of temperature distribution and displacement of carbon steel plates by FEM," in Materials Today: Proceedings, 2019, vol. 18, pp. 3380-3386, https://doi.org/10.1016/j.matpr.2019.07.264

[25] A. P. Wu, J. L. Ren, Z. S. Peng, H. Murakawa, and Y. Ueda, "Numerical simulation for the residual stresses of Stellite hard-facing on carbon steel," J. Mater. Process. Technol., vol. 101, no. 1, pp. 70-75, 2000, https://doi.org/10.1016/S0924-0136(99)00456-2

[26] Q. X. Yang, M. Yao, and J. Park, "Numerical simulation on residual stress distribution of hard-facewelded steel specimens with martensite transformation," Mater. Sci. Eng. A, vol. 364, no. 1-2, pp. 244248, 2004, https://doi.org/10.1016/j.msea.2003.08.024

[27] F. Cordovilla, Á. García-Beltrán, P. Sancho, J. Domínguez, L. Ruiz-de-Lara, and J. L. Ocaña, "Numerical/experimental analysis of the laser surface hardening with overlapped tracks to design the configuration of the process for Cr-Mo steels," Mater. Des., vol. 102, pp. 225-237, Jul. 2016, https://doi.org/10.1016/j.matdes.2016.04.038

[28] M. M. El-Sayed, A. Y. Shash, and M. Abd-Rabou, "Finite element modeling of aluminum alloy AA5083-O friction stir welding process," J. Mater. Process. Technol., vol. 252, no. November, pp. 1324, 2018, https://doi.org/10.1016/j.jmatprotec.2017.09.008

[29] F. Zanger, A. Kacaras, P. Neuenfeldt, and V. Schulze, "Optimization of the stream finishing process for mechanical surface treatment by numerical and experimental process analysis," CIRP Ann., vol. 68, no. 1, pp. 373-376, Jan. 2019, https://doi.org/10.1016/j.cirp.2019.04.086

[30] A. Ramesh, “a Review Paper on Hard-facing Processes and Materials,” Int. J. Eng. Sci. Technol., vol. 2, no. 11, pp. 6507-6510, 2010.

[31] V. Laziae et al., "Experimental determination of deformations of the hard faced samples made of steel for operating at elevated temperatures," in Procedia Engineering, 2015, vol. 111, pp. 495-501, https://doi.org/10.1016/j.proeng.2015.07.122

[32] V. Lazić, D. Arsić, R. R. Nikolić, and B. Hadzima, "Experimental Determination of Residual Stresses in the Hard-faced Layers after Hard-facing and Tempering of Hot Work Steels," in Procedia Engineering, 2016, vol. 153, pp. 392-399, https://doi.org/10.1016/j.proeng.2016.08.139

[33] S. H. Zargar, M. Farahani, and M. K. B. Givi, "Numerical and experimental investigation on the effects of submerged arc welding sequence on the residual distortion of the fillet welded plates," Proc. Inst. Mech. Eng. Part B J. Eng. Manuf., vol. 230, no. 4, pp. 654-661, 2016, https://doi.org/10.1177/0954405414560038

[34] A. K. Pandey, A. Dixit, S. Pandey, and P. M. Pandey, "Distortion control in welded structure with 
advanced submerged Arc welding," in Materials Today: Proceedings, 2019, vol. 26, pp. 1492-1495, https://doi.org/10.1016/j.matpr.2020.02.306

[35] C. R. Xavier, H. G. D. Junior, and J. A. De Castro, "An experimental and numerical approach for the welding effects on the duplex stainless steel microstructure," Mater. Res., vol. 18, no. 3, pp. 489-502, 2015, https://doi.org/10.1590/1516-1439.302014

[36] Y. Zhang and Y. Wang, "The influence of welding mechanical boundary condition on the residual stress and distortion of a stiffened-panel," Mar. Struct., vol. 65, pp. 259-270, May 2019, https://doi.org/10.1016/j.marstruc.2019.02.007

[37] Y. Fang, S. Dong, H. Jia, X. Dong, and H. Cheng, "Influence of Mesh Size on Welding Deformation and Residual Stress of Lap Joints," in Journal of Physics: Conference Series, Oct. 2018, vol. 1087, no. 4, https://doi.org/10.1088/1742-6596/1087/4/042085

[38] A. Andhale, D. W. Pande, and P. -Mech Engg, "Mesh Insensitive Structural Stress Approach for Welded Components Modeled using Shell Mesh." [Online]. Available: www.ijert.org.

[39] A. Panda, A. K. Sahoo, and A. K. Rout, "Multi-attribute decision making parametric optimization and modeling in hard turning using ceramic insert through grey relational analysis: A case study," Decis. Sci. Lett., vol. 5, no. 4, pp. 581-592, 2016, https://doi.org/10.5267/j.ds1.2016.3.001

$\begin{array}{lll}\text { Submitted: } & \text { 28.01.2021. } & \begin{array}{l}\text { Dr. Atilla Savas } \\ \text { Piri Reis University, Istanbul, Turkey }\end{array} \\ \text { Accepted: } & \text { 23.02.2021. } & \begin{array}{l}\text { asavas @ pirireis.edu.tr }\end{array}\end{array}$

